\title{
Antiglycolipid Autoantibody Detected in the Sera from Systemic Lupus Erythematosus Patients
}

\author{
Takao Hirano, Hiroshi Hashimoto, and Yuichi Shiokawa, Department \\ of Rheumatology and Collagen Disease, Juntendo University, Tokyo, Japan \\ MaSao Iwamori, and Yoshitaka Nagai, Department of Pathobiochemical Cell \\ Research, Institute of Medical Science, University of Tokyo, Tokyo, Japan \\ Masataka Kasai, Department of Tuberculosis, National Institute \\ of Health, Shinagawa, Tokyo, Japan \\ Yukiko OChial and Ko Okumura, Department of Immunology, Faculty of \\ Medicine, University of Tokyo, Tokyo, Japan
}

\begin{abstract}
A B S TRACT A high incidence of autoantibody against the neutral glycolipid "asialo $\mathrm{GM}_{1}$ " was observed in sera from patients with systemic lupus erythematosus (SLE) with neurological disorders, using an immunoflocculation test. The sera from 14 out of 17 cases of SLE with neurological disorders showed antibody activity against asialo $\mathrm{GM}_{1}$ but not against the following glycolipids: asialo $\mathrm{GM}_{2}, \mathrm{GM}_{1}$, and galactocerebroside. In another 87 cases of SLE without any history of seizures, as well as 61 cases of other autoimmune diseases (rheumatoid arthritis, progressive systemic sclerosis, mixed connective tissue disease, etc.) and 20 cases of various neurological diseases (epilepsy, multiple sclerosis, etc.), no antibody could be detected. In general, the antibody titer was high several months, even years, before and/or after the seizure, though the titer was low at the time that patients showed definite neurological symptoms. Immunochemical characterization with Sephadex G-200 chromatography and protein A-Sepharose CL-4B affinity column indicated that the antiasialo $\mathrm{GM}_{1}$ was probably an autoantibody belonging to the immunoglobulin $G$ class. The above results suggest that this newly found autoantibody plays a role in the pathogenesis of neurological disorders accompanying SLE.
\end{abstract}

\section{INTRODUCTION}

Neurological complications occur in $30-75 \%$ of all cases of systemic lupus erythematosus (SLE) ${ }^{1}(1)$. It has been

Address reprint requests to Dr. Okumura.

Received for publication 2 September 1980 and in revised form 6 October 1980.

${ }^{1}$ Abbreviation used in this paper: SLE, systemic lupus erythematosus. reported that some immunological findings, such as deposition of immune complexes in the choroid plexus, are associated with neuropsychiatric manifestations (2). It has recently been suggested that antibodies directed to neuronal antigens, including lymphocytotoxic antibodies crossreactive with the brain $(3,4)$, have some pathogenetic relevance to these neurologic manifestations. It has also been found that immunoglobulin (Ig) $\mathbf{M}$ antibodies cytotoxic to human neuroblastoma cell lines (5) and IgG antibodies reacting against neuroblastoma by indirect immunofluorescence (6) exist in the sera of SLE patients with neurological complications.

Recent studies in our laboratory identified that an antibody, antibrain-associated $\mathrm{T}$ cell antigen, which is present in heterologous antisera raised against brain tissue and which usually also reacts against $\mathrm{T}$ lymphocytes is directed against a neutral glycolipid, "asialo $\mathrm{GM}_{1}$ " (7). In view of the fact that asialo $\mathrm{GM}_{1}$ from brain has a strong antigenicity, we examined whether the antiasialo $\mathrm{GM}_{1}$ antibody would be detected in the sera of SLE patients having a history of neurological disorders.

\section{METHODS}

Patients and sera. Sera were obtained from the following patients: 104 patients with SLE, 26 with progressive systemic sclerosis, 15 with rheumatoid arthritis, 8 with mixed connective tissue disease, 7 with periarteritis nodosa, 3 with polymyositis, 2 with Sjogren syndrome, 22 with various neurological diseases ( 12 with epilepsy, 5 with multiple sclerosis, 3 with brain tumors, and 2 with Creutzfelt-Jacob disease), and 32 normal subjects. Studies were made of all patients with SLE diagnosed and followed at the Department of Rheumatology, School of Medicine, Juntendo University, Tokyo, during the period from 1974 through 1978. All the SLE and rheumatoid arthritis patients met the definite diagnostic criteria of the American Rheumatism Association for SLE or rheumatoid arthritis. The criteria of neurologic disorders 
in SLE included definite neurologic (both central and peripheral) or psychiatric abnormalities not attributable to non-SLE etiologies. Disorders thought to be due to infection or corticosteroid therapy were excluded. All the sera were stored at $-80^{\circ} \mathrm{C}$ and centrifuged at $7,500 \mathrm{~g}$ for $1 \mathrm{~h}$ before use.

Glycolipids. $\mathrm{GM}_{1}$ was isolated from bovine brain by a combination of anion-exchange chromatography and high performance adsorption chromatography (8). Asialo $\mathbf{G M}_{1}$ was prepared from $\mathrm{GM}_{1}$ by treatment with $1 \mathrm{~N}$ formic acid at $80^{\circ} \mathrm{C}$ for $1 \mathrm{~h}$, and then purified by chromatography on DEAE-Sephadex A-25 and Silica Gel 60 (Merck \& Co., Inc., Rahway, N.J.). Asialo $\mathrm{GM}_{2}$ was prepared from guinea pig erythrocytes. The purity of each ganglioside preparation was checked by thin-layer chromatography and chemical analysis as described previously (7). Galactocerebroside was also prepared from bovine brain.

Detection of antibodies. Serial dilutions of antiserum in phosphate-buffered saline $(0.02 \mathrm{ml})$ were mixed with $0.02 \mathrm{ml}$ of antigen containing $1 \mu \mathrm{g}$ of glycolipid in the form of lecithin: cholesterol micelles in a microtiter plate (7). The reaction was performed at room temperature for $60 \mathrm{~min}$, and the mixture was centrifuged at $200 \mathrm{~g}$ for $5 \mathrm{~min}$. The flocculated immune complexes were easily perceived in agglutinated form. The agglutination titer was usually decided by someone who was unaware of the diagnoses. To check the sensitivity and the reproducibility of the immunoassay, antiasialo $\mathrm{GM}_{1}$, antiasialo $\mathrm{GM}_{2}$, and antibrain-associated $\mathrm{T}$ cell antigen raised in rabbits were usually used as positive control. A titration experiment using affinity column-purified rabbit antiasialo $\mathrm{GM}_{1}$ revealed that at least $0.2 \mu \mathrm{g} / \mathrm{ml}$ of antibody is required to show positive reaction by this assay. Detection of antibodies to doublestranded DNA (anti-DNA) was carried out by the radioimmunoassays described by $\operatorname{Keiser}(9,10)$. Naturally occuring $T$ cell toxic autoantibody was detected as described previously (11). The cells were analyzed by a fluorescenceactivated cell sorter (FACS II, B-D FACS Systems, Mountain View, Calif.).

Fractionation of sera. The sera from two patients (patients 1 and 2) were fractionated by Sephadex G-200 chromatography in phosphate-buffered saline ( $\mathrm{pH}$ 7.2). IgM and IgG in the eluate were examined by immunoelectrophoresis, and the major fractions of IgM and IgG were separately pooled and concentrated. The sera from patients $1-4$ were also fractionated with a protein A-Sepharose CL-4B affinity column. The effluent and the eluate, adjusted to $\mathrm{pH} 7.0$, were collected for use. Each fraction was examined by immunoflocculation test with asialo $\mathrm{GM}_{1}$ as described above.

\section{RESULTS}

The sera were examined for their antibody activities against various glycolipid molecules purified from bovine brain tissues. The sera from 14 out of 17 cases of SLE having a history of neurological disorders showed a positive reaction with asialo $\mathrm{GM}_{1}$-conjugated miscelles in the immuno-flocculation test. In contrast, sera from another 87 cases of SLE having no history of neurological disorders did not show any antibody activity against asialo $\mathrm{GM}_{1}$, nor did sera collected from other autoimmune diseases, various neurological diseases including epilepsy, and normal individuals. None of the serum samples contained activity against other glycolipid molecules- $\mathrm{GM}_{1}$, asialo $\mathrm{GM}_{2}$, and galactocerebroside-when coupled with cholesterol: lethitin micelles in the immunoflocculation test.
TABLE I

Examination of Autoantibody in the Sera from SLE Patients with Neurological Manifestations

\begin{tabular}{ccccl}
\hline Patient & $\begin{array}{c}\text { Titer of } \\
\text { antiasialo } \\
\text { GM }^{*}\end{array}$ & NTA & $\begin{array}{c}\text { Anti- } \\
\text { DNA } \$\end{array}$ & \multicolumn{1}{c}{$\begin{array}{c}\text { Major neurological } \\
\text { manifestation }\end{array}$} \\
\hline 1 & $1: 64$ & + & - & Seizure \\
2 & $1: 32$ & - & - & Seizure \\
3 & $1: 32$ & - & - & Seizure, coma \\
4 & $1: 32$ & - & - & Seizure \\
5 & $1: 32$ & + & + & Seizure \\
6 & $1: 2$ & + & + & Peripheral neuropathy \\
7 & $1: 2$ & + & + & Seizure \\
8 & $1: 2$ & - & - & Seizure, coma \\
9 & $1: 1$ & - & - & Hemiparesis \\
10 & $1: 1$ & - & - & Seizure \\
11 & $1: 1$ & + & - & Psychosis \\
12 & $1: 1$ & + & - & Seizure, diplopia, \\
& & & & transverse myelitis \\
13 & $1: 1$ & - & + & Peripheral neuropathy \\
14 & $1: 1$ & + & - & Seizure, coma \\
15 & $0^{\text {11 }}$ & + & - & Seizure \\
16 & 0 & - & + & Seizure \\
17 & 0 & - & + & Seizure \\
\end{tabular}

* Titer of antiasialo $\mathrm{GM}_{1}$ was measured by immunoflocculation test as described in Methods.

\ NTA (natural T cell toxic autoantibody) was detected by fluorescence-activated cell sorter.

$\S$ More than $30 \%$ of activity against native DNA, calculated as follows, was scored as + :

Percent activity

$$
=\frac{(\text { cpm sample })-(\mathrm{cpm} \text { blank })}{\mathrm{cpm} / \mu \mathrm{g}\left[{ }^{3} \mathrm{H}\right] \mathrm{nDNA}} \cdot(\text { dilution factor })
$$

"Antibody was not detected by immunoflocculation test.

Detailed findings of 17 cases of SLE having history of neurological disorders are depicted in Table $I$. No association between the titer of antiasialo $\mathrm{GM}_{1}$ and other autoantibodies such as natural $\mathrm{T}$ cell toxic autoantibody and anti-DNA was observed.

To determine whether or not this antiglycolipid antibody is related to the occurrence of the neurological involvement in SLE patients, a time-course study was performed by measuring the titers of antiasialo $\mathrm{GM}_{1}$ at various times in course of the disease. Actually, the serum samples of the patients that had been collected at several-month intervals were examined retrospectively after the history of seizure was obtained. Fig. 1 represents the changes of the serum antibody titer from four patients with severe neurological manifestations, which occurred only during the period shown in Fig. 1 in their clinical history. Serially collected serum samples from the patients who repeated neurological seizures were not available. It was found that the titer against asialo $\mathrm{GM}_{1}$ decreased rapidly when the seizure 


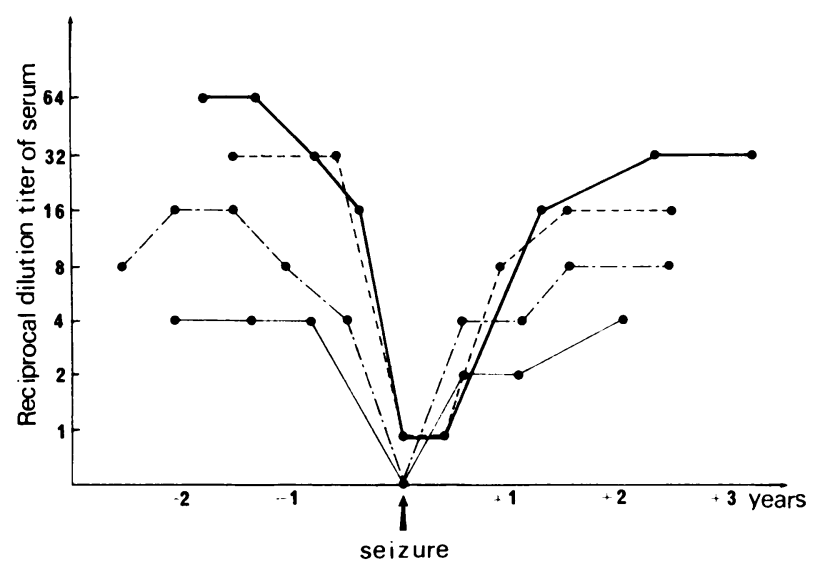

FIGURE 1 Serial determinations of antiasialo $\mathrm{GM}_{1}$ antibodies in the sera from four patients with severe neurological manifestations (patients 1-4). The arrow indicates when seizures occurred frequently. The serum samples during heightened seizure activity were drawn within 1 wk after the onset of seizure. The right side of the horizontal line shows years after seizures, the left side, years before seizures.

started to appear, and that the titer increased again after the seizure had ceased. In all four cases examined, their time courses showed a similar pattern, whereas no antibody activity was observed in the sera of epilepsy obtained at various intervals after the seizure. Thus the appearance and decrease of this antibody was shown to have a close relationship to the onset of the neurological manifestations in SLE.
A study was performed to learn what immunoglobulin class this antiglycolipid antibody belongs to. The sera from two SLE patients having high antiasialo $\mathrm{GM}_{1}$ activity were fractionated on a Sephadex G-200 column and the two fractions corresponding to IgM and IgG were collected and concentrated for analysis of antiasialo $\mathrm{GM}_{1}$ activity. As depicted in Fig. 2, fraction (Fr.) II, which contains IgG, showed a positive reaction against asialo $\mathrm{GM}_{1}$, whereas Fr. I, in which most IgM was eluted, had no antibody activity. Furthermore, using the protein A column elution study, it was found that this antibody mainly belongs to the human IgG classes. The titer of antiasialo $\mathrm{GM}_{1}$ antibody of original serum was 1:64; that of the acid eluate was $1: 16$; no activity was detected in the column effluent without acid.

\section{DISCUSSION}

The results presented here indicate that a newly found autoantibody against the neutral glycolipid asialo $\mathrm{GM}_{1}$ is closely associated with the neurological manifestations accompanying SLE. Though the possibility is not excluded that other SLE patients have the antibody in a titer too low to be detected at present, the apparent correlation between the fluctuation of antiasialo $\mathrm{GM}_{1}$ titer and neurological seizures, is nonetheless of great interest. Though asialo $\mathrm{GM}_{1}$ is a minor component in the brain tissue and is difficult to detect by biochemical analysis, it is tempting to assume that this antibody reacts with asialo $\mathrm{GM}_{1}$-bearing neural

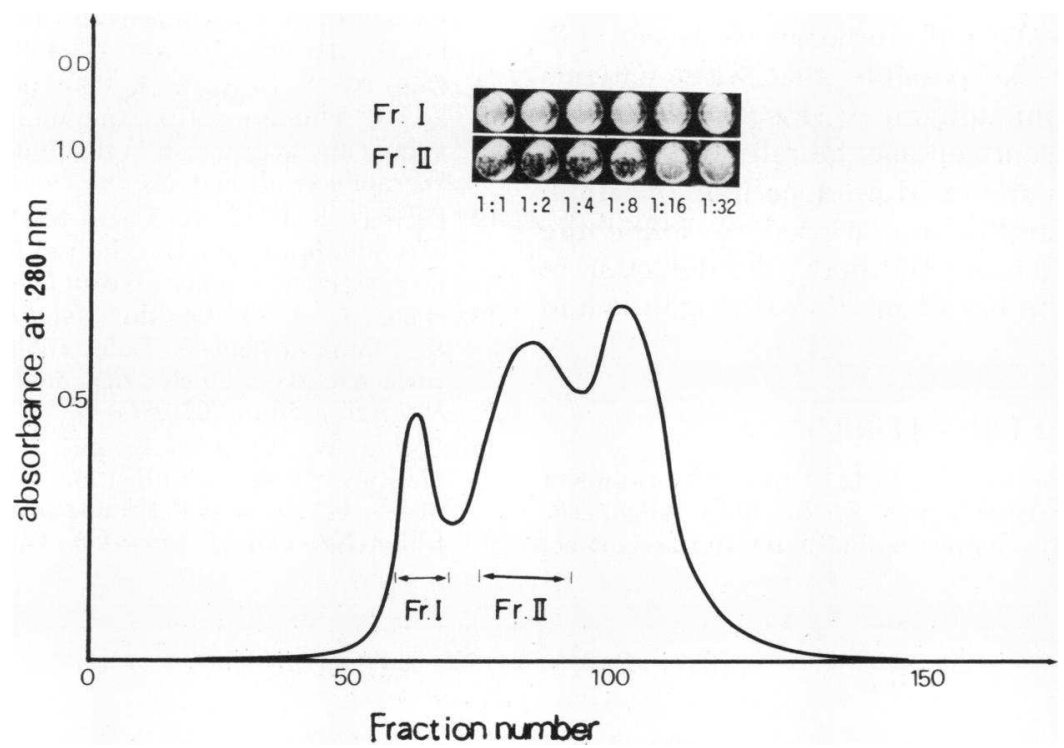

Figure 2 Sephadex G-200 profile of the serum from SLE patient $1.0 .8 \mathrm{ml}$ serum was applied to a column of bed volume $(2.2 \times 62 \mathrm{~cm})$ and eluted with phosphate-buffered saline $(\mathrm{pH} 7.2)$. The peak fractions of Fr. I and Fr. II were examined by an immunoflocculation test. As shown in the figure, antiasialo $\mathrm{GM}_{1}$ activity was not detected in Fr. I, but was observed at 1:8 dilution in Fr. II as an agglutinated form of a flocculated immune complex. 
cells to cause various neurological manifestations. It may be possible that some pathological changes in the brain such as vasculitis, which is often present in SLE, destroy the blood-brain barrier, making it easier for the antibody to pass into the brain tissue. Our recent immunofluorescence studies indicate that the rabbit antiasialo $\mathrm{GM}_{1}(7)$ as well as sera from SLE patients having antiasialo $\mathrm{GM}_{1}$ activities, reacts with several cell lines of neural origin: mouse neuroblastoma (C1300-Y1) and astrocytoma (GA223a). Since the above results indicate that the components reacting with asialo $\mathrm{GM}_{1}$ in the sera from SLE belong mainly to the IgG class, and several IgG subclasses fix complement, the reaction of this autoantibody with asialo $\mathrm{GM}_{1}$-bearing neural cells may induce an activation of complements resulting in cytotoxicity to the brain tissue. Karpiak et al. (12) reported that the injection of heterologous antiserum against brain gangliosides directly into the brain caused an epileptic seizure. Since the preceding blood sample was drawn several months before the seizure, one cannot be sure just when the fall in antibody occurred in relation to the seizure or, for that matter, how rapidly the levels were restored. Though it is not at present possible to detect glycolipid antigen in the sera by any immunological means, it may be postulated that antigen is released at the time of seizure, thereby masking or removing the preexisting antibody.

The mechanisms that produce this autoantibody in SLE are unknown. However, in addition to the fact that asialo $\mathrm{GM}_{1}$ is highly immunogenic (7), several laboratories have found that various types of lymphoid cells are able to react with antiasialo $\operatorname{GM}_{1}(13,14)$. Therefore, it may be possible that SLE patients initially respond to this antigen expressed on lymphoid cells. Alternatively, antigen may be released from the brain into the circulation and produce immunization. Although further studies are needed to define the pathogenic role of this autoantibody, the detection of this antibody may be useful in clinical diagnosis and treatment.

\section{ACKNOWLEDGMENTS}

The authors thank Professor T. Tada of the Department of Immunology, University of Tokyo, for his help and Ms. Y. Yamaguchi and Ms. M. Ichikawa for secretarial assistance.
This work was supported by the Ministry of Education, Culture and Science, and the Ministry of Health, Japan.

\section{REFERENCES}

1. Hadler, N. M., R. D. Gerwin, M. M. Frank, J. N. Whitaker, M. Baker, and J. Decker. 1973. Fourth component of complement in the cerebrospinal fluid in systemic lupus erythematosus. Arthritis Rheum. 16: 507-521.

2. Atkins, C. J., J. J. Kondon, F. P.Quismorio, and G. J. Frior. 1972. The choroid plexus in systemic lupus erythematosus. Ann. Intern. Med. 76: 65-72.

3. Bluestein, H. G., and N. J. Zvaifler. 1976. Brain-reactive lymphocytotoxic antibodies in the serum of patients with systemic lupus erythematosus. J. Clin. Invest. 57: 509-516.

4. Bresnihan, B., M. Oliver, R. Grigor, and G. R. V. Hughes. 1977. Brain reactivity of lymphocytotoxic antibodies in systemic lupus erythematosus with and without cerebral involvement. Clin. Exp. Immunol. 30: 333-337.

5. Bluestein, H. G. 1977. Antineuronal activity in systemic lupus erythematosus serum. Arthritis Rheum. 20: 109.

6. Wilson, H. A., and J. B. Winfield, R. G. Lahita, and D. Koffler. 1979. Association of IgG anti-brain antibodies with central nervous system dysfunction in systemic lupus erythematosus. Arthritis Rheum. 22: 458-562.

7. Kasai, M., M. Iwamori, Y. Nagai, K. Okumura, and T. Tada. 1980. A glycolipid on the surface of mouse natural killer cells. Eur. J. Immunol. 10: 175-180.

8. Nagai, Y., and M. Iwamori. 1980. A new approach to the analysis of ganglioside molecular species. Adv. Exp. Med. Biol. 125: 13-21.

9. Ginsberg, B., and H. Keiser 1973. A millipore filter assay for antibodies to native DNA in sera of patients with systemic lupus erythematosus. Arthritis Rheum. 16: 199-207.

10. Keiser, H. 1973. Preparation of ${ }^{125}$ I-labeled native DNA for use in radioimmunoassays for anti-native-DNA antibodies. Arthritis Rheum. 16: 468-470.

11. Goto, M., Y. Horiuchi, K. Okumura, T. Tada, M. Kawata, and K. Ohmori. 1979. Immunological abnormalities of aging: an analysis of $\mathrm{T}$ lymphocyte subpopulations of Werner's syndrome. J. Clin. Invest. 64: 695-699.

12. Karpiak, S. E., L. Graf, and M. M. Rapport. 1976. Antiserum to brain gangliosides produces recurrent epileptiform activity. Science (Wash. D. C.). 194: 735-737.

13. Nakahara, K., T. Ohashi, T. Oda, T. Hirano, M. Kasai, K. Okumura, and T. Tada. 1980. Asialo $\mathrm{GM}_{1}$ as a cell surface marker detected in acute lymphoblastic leukemia. N. Engl. J. Med. 302: 674-677.

14. Young, W. W., S. Hakomori, J. M. Durdik, and C. S. Henney. 1980. Identification of ganglio-N-tetraosylceramide as a new cell surface marker for murine natural killer (NK) cells. J. Immunol. 124: 199-202. 